\title{
SHORT
}

COMMUNICATIONS

\section{Acupalpus parvulus (Sturm), a Ground-Beetle Species Found in Xinjiang, New to the Fauna of China (Coleoptera, Carabidae: Harpalini)}

\author{
I. I. Kabak ${ }^{a}$ and B. M. Kataev ${ }^{b}$ \\ ${ }^{a}$ All-Russia Institute of Plant Protection, Pushkin, St. Petersburg, 196608 Russia \\ e-mail: ilkabak@yandex.ru \\ ${ }^{b}$ Zoological Institute, Russian Academy of Sciences, St. Petersburg, 199034 Russia \\ e-mail: harpal@zin.ru \\ Received February 23, 2016
}

\begin{abstract}
Acupalpus (s. str.) parvulus (Sturm, 1825) is recorded for the Chinese fauna for the first time. The species was collected in the Kara-Irtysh (= Ertix) River valley and at Lake Ulungur in the northern part of the Xinjiang-Uygur Autonomous Region.
\end{abstract}

DOI: $10.1134 / \mathrm{S} 0013873816030167$

The present study is based on the material collected by I.I. Kabak from several localities in the Chernyi Irtysh River valley in the north of Xinjiang in 2015. The specimens examined are deposited in I.A. Belousov's and I.I. Kabak's collections (St. Petersburg).

Acupalpus (s. str.) parvulus (Sturm, 1825)

Material. China. Xinjiang: Kara-Irtysh (= Ertix) River, Burqin Town, 47 $4135^{\prime \prime N} / 86^{\circ} 51^{\prime} 54^{\prime \prime} \mathrm{E}$, $h \sim 410$ m, 31.VII.2015 (I.I. Kabak), 2 đ; Lake Ulungur, $20 \mathrm{~km}$ WNW of Beitun Town, $47^{\circ} 25^{\prime} 19^{\prime \prime} \mathrm{N} /$ $87^{\circ} 34^{\prime} 00^{\prime \prime} \mathrm{E}, h \sim 470 \mathrm{~m}, 3 . \mathrm{VIII} .2015$ (I.I. Kabak), 2 Љ’;

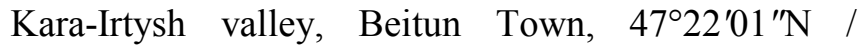
$87^{\circ} 48^{\prime} 38^{\prime \prime} \mathrm{E}, h \sim 515$ m, 3.VIII.2015 (I.I. Kabak), 1 ㅇ.

Distribution. This species is widely distributed in Eurasia; its range covers entire Europe, Asia Minor, Transcaucasia, Iran, Afghanistan, Northern Pakistan, Middle Asia, Kazakhstan, and Siberia (Jaeger and Kataev, 2003; Jaeger, 2011) to the east as far as the south of Krasnoyarsk Territory (Kryzhanovskij et al., 1995). The species has not been recorded earlier for the territory of China; it was found in the northern part of the Xinjiang-Uygur Autonomous Re- gion, in the Chernyi Irtysh River valley and near Lake Ulungur.

\section{ACKNOWLEDGMENTS}

The study of B.M. Kataev is performed within the frame of the state theme no. 01201351189 of the Zoological Institute, Russian Academy of Sciences, St. Petersburg, with financial support of the Russian Foundation for Basic Research (grant no. 16-0400412).

\section{REFERENCES}

1. Jaeger, B., "New and Additional Distribution Data of the Genus Acupalpus Latreille 1829 from the Middle East and Adjacent Areas (Coleoptera, Carabidae, Harpalini, Stenolophina)," Linzer Biol. Beiträge 43 (1), 763-775 (2011).

2. Jaeger, B. and Kataev, B.M., "Stenolophina," in Catalogue of Palaearctic Coleoptera. Vol. 1. Archostemata-Myxophaga-Adephaga (Apollo Books, Stenstrup, 2003), pp. 397-406.

3. Kryzhanovskij, O.L., Belousov, I.A., Kabak, I.I., Kataev, B.M., Makarov, K.V., and Shilenkov, V.G., A Checklist of the Ground-Beetles of Russia and Adjacent Lands (Insecta, Coleoptera, Carabidae) (Pensoft Publ., Sofia, 1995) (Moscow: Series Faunistica, No. 3). 